\title{
Increasing Incidence of Primary Aldosteronism in Patients Investigated for Resistant Hypertension: An Observational Study from a Nephrology Unit
}

\section{Antonio Del Giudice ${ }^{1 *}$, Chiara Di Giorgio ${ }^{2}$, Giuseppe Di Giorgio ${ }^{1}$, Rachele Grifa ${ }^{1}$, Vincenzo Lauriola ${ }^{1}$, Filomena Miscio ${ }^{1}$, Matteo Piemontese ${ }^{1}$, Michele Prencipe ${ }^{1}$, Antonio Scarlatella ${ }^{1}$, Andrea Fontana ${ }^{3}$, Massimiliano Copetti ${ }^{3}$, Fabio Pellegrini ${ }^{3}$ and Filippo Aucella ${ }^{1}$}

${ }^{1}$ IRCCS Casa Sollievo della Sofferenza Hospital, Department of Medical Sciences, Unit of Nephrology, San Giovanni Rotondo, FG, Italy

${ }^{2}$ Department of Emergency and Organ Transplantation, University Hospital of Bari, Bari, Italy

${ }^{3}$ IRCCS Casa Sollievo della Sofferenza Hospital, Unit of Biostatistics, San Giovanni Rotondo, FG, Italy

\begin{abstract}
Introduction: Primary Aldosteronism (PA) is a secondary form of hypertension characterized by an autonomous and inappropriately high production of aldosterone. Its prevalence is $5-12 \%$ and the two main subtypes are the Bilateral Adrenal Hyperplasia (BAH) and the Aldosterone-Producing Adenoma (APA). In this study, we report the results of an evalutation of some patients diagnosed with PA in a Nephrology Unit between 1987-2011.

Patients and methods: As much as 54 patients were screened for PA by measuring Plasma Aldosterone Concentration (PAC) and Plasma Renin Activity (PRA), and by calculating the aldosterone/renin ratio (ARR). Confirmation tests were performed on 47 patients with $P A C \geq 15 \mathrm{ng} / \mathrm{dL}$ and $A R R \geq 40$. Subtype diagnosing was possible through adrenal CT scan, scintigraphy and adrenal venous sampling.

Results: As much as 31 patients were diagnosed with PA. In 17 of them, the concordance of CT, scintigraphy and AVS findings made it possible to determine the subtype diagnosis: BAH in 10 and APA in 7 patients.

Conclusions: Our results confirm the increasing frequency of diagnosis of PA among patients investigated for resistant hypertension. Early detection of PA in nephrological settings is important because of the relationship between aldosterone and kidney function.
\end{abstract}

\section{Introduction}

Primary Aldosteronism (PA) is a condition characterized by an inappropriately high production of aldosterone, which is relatively autonomous from the renin-angiotensin system, and nonsuppressible by sodium loading [1].

First described by Conn in 1955 [2], PA usually, but not invariably, presents the triad of hypertension, hypokalemia and metabolic alkalosis.

The two main forms, or subtypes, of PA are the Bilateral Adrenal Hyperplasia (BAH), or Idiopatic Hyper Aldosteronism (IHA), with a relative frequency of $65 \%$, and the aldosterone-producing adenoma (APA), with a relative frequency of $30 \%$.

Less common forms are the Unilateral Adrenal Hyperplasia (UAH), that is the micro- or macronodular hyerplasia of the zona glomerulosa of the adrenal cortex, mainly involving one of the adrenal glands (3\%); and the bilateral adrenal hyperplasia, micro- or macronodular (1\%) $[3,4]$ Even if sporadic, PA may be familial and manifests in at least two forms [5,6]: the Familial Hyperaldosteronism type I (FH-I), or Glucocorticoid-Remediable Aldosteronism (GRA), very rare $(<1 \%)$, which has an autosomal dominant mode of transmission and is caused by an adrenocorticotropic hormone-regulated, hybrid CYP11B1/ CYP11B2 gene $[7,8]$; and the familial hyperaldosteronism type II (FH-II), which is the familial form of APA or BAH or both. FH-II relative frequency is unknown, but it is considered to be at least 5 times higher than that of FH-I. This form is clinically indistinguishable from apparently non-familial forms of PA, is not glucocorticoid-remediable and is thought to have a variable mode of transmission: autosomal dominant in some families and possibly recessive in others. Regarding FH-II, linkage studies have implicated a locus at chromosome 7p22 in some of the families studied, thus allowing a probable genetic heterogeneity $[9,10]$.

Finally, among the rare forms of PA, there are the pure aldosteroneproducing adrecortical carcinomas (1\%) and the ectopic aldosteroneproducing tumors, such as some tumors of kidney and ovary $(<1 \%)$ [11]. Although the prevalence of PA is still debated and has not been accurately defined yet, it seems to be higher than suggested in the past. Conn himself, who was the first to describe this condition [2], later hypothesized that $20 \%$ of the hypertensive subjects could be suffering from PA [12].

However, this hypothesis was not confirmed in the following years because of the lack of reliable methods of essay for plasma renin activity and plasma aldosterone [13].

Therefore, for a long time PA was thought to be a rare and relatively benign form of hypertension, with an estimated prevalence of approximately $1 \%$ among non selected hypertensives. On the other hand, among the patients suffering from resistant hypertension, the

*Corresponding author: Antonio Del Giudice, IRCCS Casa Sollievo della Sofferenza Hospital, Department of Medical Sciences, Unit of Nephrology Viale Cappuccin 71013 San Giovanni Rotondo, FG, Italy, E-mail: a.delgiudice@operapadrepio.it

Received March 29, 2012; Accepted April 16, 2012; Published April 18, 2012

Citation: Del Giudice A, Di Giorgio C, Di Giorgio G, Grifa R, Lauriola V, et al (2012) Increasing Incidence of Primary Aldosteronism in Patients Investigated for Resistant Hypertension: An Observational Study from a Nephrology Unit. J Nephrol Therapeutic S3:007. doi:10.4172/2161-0959.S3-007

Copyright: ( 2012 Del Giudice A, et al. This is an open-access article distributed under the terms of the Creative Commons Attribution License, which permits unrestricted use, distribution, and reproduction in any medium, provided the original author and source are credited. 
Citation: Del Giudice A, Di Giorgio C, Di Giorgio G, Grifa R, Lauriola V, et al. (2012) Increasing Incidence of Primary Aldosteronism in Patients Investigated for Resistant Hypertension: An Observational Study from a Nephrology Unit. J Nephrol Therapeutic S3:007. doi:10.4172/21610959.S3-007

Page 2 of 5

prevalence has been estimated 3\% to 13\%, with some studies reporting figures even up to $20 \%$. As a consequence, an "epidemic" of PA was hypothesized $[14,15]$.

In a prospective multicentre study carried out in 2006, Rossi et al. [16] reported a $11.2 \%$ prevalence of PA in 1,125 newly diagnosed hypertensive patients referred to hypertension centers.

On the other hand, in a retrospective observational study conducted in 2008, Douma et al. [17] reported a prevalence of PA of $11.3 \%$ among 1,616 patients with resistant hypertension who had been evaluated over 20 years. Although the prevalence was so high, it was substantially lower than previously reported. On the basis of this finding, the authors assumed that the prevalence of primary hyperaldosteronism in the general unselected hypertensive population was much lower than that reported until then [17]. Hence, prevalence of PA could currently be estimated at $5-12 \%$, suggesting that PA may be the most common endocrine form of hypertension [18].

Moreover, there is an emerging evidence of association between PA and renal injury [19-23] as well as with cardiovascular events [24,25] and metabolic syndrome [26].

The aim of this study is to report the results of an observational evalutation of patients who were investigated for resistant hypertension in our Nephrology Unit between 1987 and 2011 and were diagnosed with PA.

\section{Patients and Methods}

All 54 patients, 35 females and 19 males of a mean age of $47.7 \pm$ 9.3 (range: $30-73$ ), were selected from hospital records and history case forms. All of them had either suspended antihypertensive therapy or were receiving $a$-blockers treatment. All of the patients had been screened for PA by measuring serum potassium, Plasma Aldosterone Concentration (PAC) and Plasma Renin Activity (PRA), both after night's sleep in bed and after 3 hours of standing and walking. The PAC/PRA ratio (Aldosterone/Renin Ratio, ARR) was calculated in all cases. For this calculation, lower values of PRA were arbitrarily set to $0.2 \mathrm{ng} / \mathrm{mL} / \mathrm{h}$, due to the poor accuracy of assays of PRA at its lower values and the influence of PRA, as denominator, on the ARR $[1,16]$. In 2003, we introduced confirmation/suppression tests in the diagnostic procedure: the suppression test, which was performed on 34 patients, with infusion of the isotonic saline solution in 4 hours (Saline Infusion Test, SIT) and re-evaluation of PAC; and the captopril administration test, with $50 \mathrm{mg}$ per os, performed on 3 patients, with re-evaluation of ARR after 2 hours. CT of adrenal glands was performed on 43 patients, adrenal scintigraphy with ${ }^{131} \mathrm{I}$ - cholesterol was performed on 21 patients and adrenal venous sampling (AVS) on 8 patients. Finally, genetic testing for the familial hyperaldosteronism type I (GRA) was performed on 2 patients. For the diagnosis of PA, we adopted the following cut-off values: $\mathrm{PAC} \geq 15 \mathrm{ng} / \mathrm{dL}, \mathrm{ARR} \geq 40 \mathrm{ng} / \mathrm{dL}$ of PAC per $n g / m L / h$ of PRA [27,28]; for confirmation, values of $\mathrm{PAC} \geq 6$ $\mathrm{ng} / \mathrm{dL}$ after SIT or of ARR $\geq 40$ after captopril. CT, scintigraphy and AVS - when performed - made the subtype diagnosis possible [1,28]. The statistical comparison between demographic and biochemical characteristics in patients with BAH and APA was made by means of the Mann-Whitney test $U$ for continuous variables and with the Fisher exact test for categorical variables.

\section{Results}

In all of the 54 patients evaluated, PAC was found to be $>15 \mathrm{ng} / \mathrm{dL}$ and $\mathrm{PRA}<1 \mathrm{ng} / \mathrm{mL} / \mathrm{h}$. During re-examination of cases, using the cut- off values indicated above, ARR was found to be $<40 \mathrm{ng} / \mathrm{dL}$ of PAC per $\mathrm{ng} / \mathrm{mL} / \mathrm{h}$ of PRA in 7 patients; the diagnosis of PA was consequently excluded in these patients. In 47 patients, ARR was found to be $\geq 40 \mathrm{ng} /$ $\mathrm{dL}$ of PAC per $\mathrm{ng} / \mathrm{mL} / \mathrm{h}$ of PRA. The diagnosis of PA was confirmed in 31 of them: in 25 patients, PAC was $\geq 6 \mathrm{ng} / \mathrm{dL}$ after SIT; in 1 patient, ARR was $\geq 40 \mathrm{ng} / \mathrm{dL}$ of PAC per $\mathrm{ng} / \mathrm{mL} / \mathrm{h}$ of PRA after captopril; in another patient, who was found with a negative SIT, PA was confirmed by AVS; in 4 patients, who did not undergo confirmation/suppression tests, PA was confirmed subsequently by the hystologic examination of the adenoma removed with surgery. In the remaining 16 patients with $\mathrm{PAC}>15 \mathrm{ng} / \mathrm{dL}, \mathrm{PRA}<1 \mathrm{ng} / \mathrm{mL} / \mathrm{h}$ and $\mathrm{ARR} \geq 40 \mathrm{ng} / \mathrm{dL}$ of PA per $\mathrm{ng} / \mathrm{mL} / \mathrm{h}$ of PRA, diagnosis of PA was not confirmed: in 12 of them the tests had not been performed; in 2 of them, PAC after SIT was found to be $<6 \mathrm{ng} / \mathrm{dL}$; in other 2, ARR after captopril was $<40 \mathrm{ng} /$ $\mathrm{dL}$ of PA per $\mathrm{ng} / \mathrm{mL} / \mathrm{h}$ of PRA. Genetic testing for the familial form of GRA was performed on 2 patients; in both cases it was negative. The concordance of CT scans, scintigraphy and AVS findings made it possible to determine the diagnosis of the subtype in 17 cases: Bilateral Adrenal Hyperplasia (BAH) in 10 patients and Aldosterone-Producing Adenoma (APA) in 7 patients (Figure 1, Table 1 and Table 2).

In particular, through AVS, which was performed in 8 patients, it was possible to confirm the diagnosis of aldosterone-producing adenoma (APA) in 1 patient, and to make a diagnosis of bilateral adrenal hyperplasia (BAH) in 3 patients; in 4 cases, AVS was not possible because the right adrenal vein was difficult to catheterize. However, in one of these four last cases, clinical data (less than 40 years of age and resistant hypertension), laboratory data (serum potassium $<3.0 \mathrm{mEq} / \mathrm{L}, \mathrm{PAC}>25 \mathrm{ng} / \mathrm{L}$ ) and instrumental data (CT showed the presence of a lump of $>10 \mathrm{~mm}$ in one of the adrenal glands) were considered "suspicious" criteria, meaning criteria with a high probability of APA $[4,28]$.

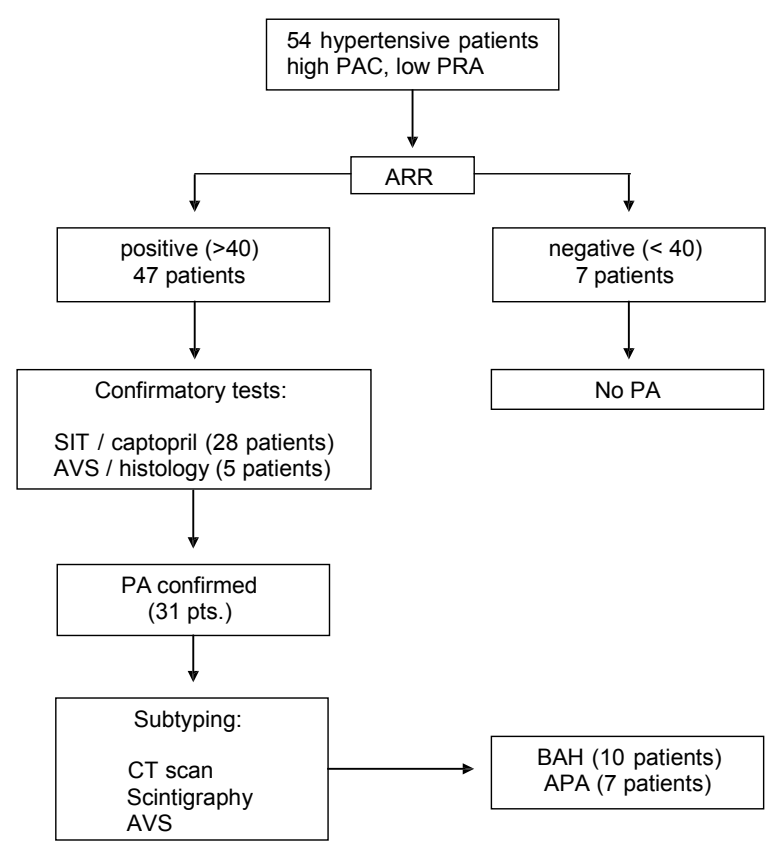

Figure 1: Flow chart of diagnostic workup for primary. Idosteronism PAC, plasma aldosterone concentration; PRA, plasma renin activity; ARR, aldosterone/renin ratio; PA, primary aldosteronism; SIT, saline infusion test; AVS, adrenal venous sampling; CT, computed tomography; BAH, bilateral adrenal hyperplasia; APA, aldosterone- producing adenoma. 
Citation: Del Giudice A, Di Giorgio C, Di Giorgio G, Grifa R, Lauriola V, et al. (2012) Increasing Incidence of Primary Aldosteronism in Patients Investigated for Resistant Hypertension: An Observational Study from a Nephrology Unit. J Nephrol Therapeutic S3:007. doi:10.4172/21610959.S3-007

Page 3 of 5

\begin{tabular}{|l|c|l|}
\hline \multicolumn{1}{|c|}{ Variable } & Category & PA patients (n=31) \\
\hline Age (years) & -- & $49.77 \pm 9.85($ range 31 - 73) \\
\hline \multirow{2}{*}{ Sex $(\mathrm{M} / \mathrm{F})$} & M & $10(32.26 \%)$ \\
\hline Serum potassium $(\mathrm{mEq} / \mathrm{L})$ & F & $21(67.74 \%)$ \\
\hline PAC recumbent $(\mathrm{ng} / \mathrm{dL})$ & -- & $3.71 \pm 0.74$ \\
\hline PAC upright $(\mathrm{ng} / \mathrm{dL})$ & -- & $27.30 \pm 17.45$ \\
\hline PRA recumbent $(\mathrm{ng} / \mathrm{mL} / \mathrm{h})$ & -- & $45.29 \pm 26.07$ \\
\hline PRA upright $(\mathrm{ng} / \mathrm{mL} / \mathrm{h})$ & -- & $0.27 \pm 0.17$ \\
\hline ARR recumbent $(\mathrm{ng} / \mathrm{dL})$ & -- & $0.41 \pm 0.38$ \\
\hline ARR upright $(\mathrm{ng} / \mathrm{dL})$ & -- & $118.75 \pm 91.17$ \\
\hline PAC after saline $(\mathrm{ng} / \mathrm{dL})$ & -- & $164.86 \pm 125.13$ \\
\hline
\end{tabular}

Table 1: Demographic and biochemical characteristics of patients with primary aldosteronism. Data were reported as means \pm SD or frequencies and percentages for continuous and categorical variables, respectively. PA, primary aldosteronism; PAC, plasma aldosterone concentration; PRA, plasma renin activity; ARR, aldosterone/renin ratio.

On the whole, the diagnosis of PA was made for 31 patients. For 5 patients the diagnosis was made over 15 years between 1987 and 2002, with an incidence of 0.33 cases per year; and for 26 patients, it was made over 9 years between 2003 and 2011, with an incidence of 2.88 cases/year.

\section{Discussion}

For a long time PA has been thought to be a relatively benign and rare form of hypertension that could only be detected in the presence of hypokalemia. Although the prevalence of PA is still debated and has not been accurately defined yet, it is currently considered to be higher than suggested in the past, and it is estimated about $5-12 \%$ of hypertensive patients $[16,17,27]$ Recent changes in the perceived epidemiology of PA appear related to an increased investigation and detection in normokalemic patients too [29].Some authors hypothesize

that such a prevalence could be even higher (up to 15-20\%) in selected groups of patients, such as those suffering from resistant hypertension, type 2 diabetes mellitus and sleep apnea syndrome [29].

The use of ARR as screening test for PA, also in primary care settings [30], and of suppression tests, which were meant to confirm or to exclude nonsuppressable high plasma aldosterone levels, could explain the higher prevalence rate of PA recently reported. In our study, the use of ARR as screening test for PA and of confirmation tests made it possible to make the conclusive diagnosis with an increasing frequency during the recent years. However, today the uselfuness of ARR is still debated because there are some doubts on its reliability, in terms of reproducibility, sensitivity and specificity. Moreover, several factors could influence ARR, like the posture, the time of the day of blood sampling and the possibile use of antihypertensive drugs [1,31-33]. Also, there is a lack of consensus on the types of patients' populations in which the ARR should be used as screening test for PA and on clear cut-off values to adopt. For example, Montori and Young, in a systematic review of 16 studies (for a total of 3,136 patients), reported that the thresholds for the ARR used varied between 7.2 and $100.0 \mathrm{ng} / \mathrm{dL}$ per $\mathrm{ng} / \mathrm{mL}$ per hour [34,35].

In the screening for PA, we tried to comply with the criteria adopted by other authors $[27,28]$ and to follow the suggestions of the guidelines of the Endocrine Society [1]. In fact, for ARR, we decided to use cut-off levels of $\geq 40 \mathrm{ng} / \mathrm{dL}$ of PA per $\mathrm{ng} / \mathrm{mL} / \mathrm{h}$ of PRA, in addition to $\mathrm{PAC} \geq 15 \mathrm{ng} / \mathrm{mL}$ [4]. Independently from the underlying pathologic condition, the overproduction of aldosterone in PA causes sodium and water retention, hypertension, cardiovascular damage, suppression of plasma renin, and potassium excretion that, if prolonged, can lead to hypokalemia [1]. However, contrary to what was initially believed, both spontaneous and diuretic-induced hypokalemia (i.e. serum potassium $<3.5 \mathrm{mEq} / \mathrm{L}$ ) are now considered not necessary for diagnostic screening for PA. This was noted by Conn in 1965 [36] and also confirmed by later studies in which most of the patients diagnosed with PA resulted to be normokalemic, while hypokalemia in different cases and geographical areas has been detected in less than half of cases and in variable percentages: from $9-37 \%$, as reported by Mulatero et al. in a

\begin{tabular}{|c|c|c|c|c|}
\hline Variable & Category & ВАH & APA & $p$-value \\
\hline $\mathrm{n}$ & & 10 & 7 & -- \\
\hline Age (years) & & $52.00 \pm 8.43($ range $42-70)$ & $49.14 \pm 8.97$ (range $31-61)$ & 0,961 \\
\hline \multirow[b]{2}{*}{$\operatorname{Sex}(M / F)$} & M & $4(40.0 \%)$ & $1(14.29 \%)$ & \multirow[b]{2}{*}{0,338} \\
\hline & $\mathrm{F}$ & $6(60.0 \%)$ & $6(85.71 \%)$ & \\
\hline Serum potassium (mEq/L) & & $3.91 \pm 0.34$ & $2.62 \pm 0.38$ & 0,004 \\
\hline PAC recumbent (ng/dL) & & $20.26 \pm 7.97$ & $49.23 \pm 24.68$ & 0,009 \\
\hline PAC upright (ng/dL) & & $32.79 \pm 9.18$ & $63.60 \pm 41.25$ & 0,072 \\
\hline PRA recumbent (ng/mL/h) & & $0.28 \pm 0.12$ & $0.31 \pm 0.27$ & 0,562 \\
\hline PRA upright (ng/mL/h) & & $0.48 \pm 0.29$ & $0.22 \pm 0.03$ & 0,057 \\
\hline ARR recumbent (ng/dL) & & $84.07 \pm 38.18$ & $217.25 \pm 147.06$ & 0,034 \\
\hline ARR upright (ng/dL) & & $88.51 \pm 44.41$ & $283.50 \pm 137.58$ & 0,015 \\
\hline PAC after saline (ng/dL) & & $10.75 \pm 4.63$ & $23.12 \pm 9.09$ & 0,113 \\
\hline
\end{tabular}

Table 2: Comparison between BAH and APA subtypes. Data were reported as means \pm SD or frequencies and percentages for continuous and categorical variables, respectively.

Two sided $p$-values for continuous variables refer to Mann-Whitney test $U$.

Two sided $p$-values for categorical variables refer to Fisher exact test. 
Citation: Del Giudice A, Di Giorgio C, Di Giorgio G, Grifa R, Lauriola V, et al. (2012) Increasing Incidence of Primary Aldosteronism in Patients Investigated for Resistant Hypertension: An Observational Study from a Nephrology Unit. J Nephrol Therapeutic S3:007. doi:10.4172/21610959.S3-007

Page 4 of 5

study conducted in centers from 5 continents [27], to 18\%, in Japanese reports [37,38], to $9.6 \%$, in the Italian prospective study of prevalence (the PAPY study) [16], to $45.5 \%$, in the Greek retrospective study of Douma et al. [17]. This suggests that the presence of hypokalemia has low sensitivity and specificity, and has a low predictive value for the diagnosis of PA [1]. As a consequece, excluding normokalemic hypertensives from screening can imply the risk of underestimation of the true incidence of PA [9]. However, it must be said that in the PAPY study spontaneous hypokalemia was observed in $48 \%$ of the patients with APA and in only $16.9 \%$ of those with IHA [16]. In our study, we observed hypokalemia in $23.4 \%$ of all the patients diagnosed with and affected by $\mathrm{PA}$ and, moreover, in 1 of 10 patients with $\mathrm{BAH}$ and in the 7 patients with APA (data not shown).

In this regard, the two main subtypes of PA, i.e. APA and HIA (or BAH), can be diagnosed on the basis of four modified "corners score criteria" [16,39]. More exactly, APA can be established when all of the following criteria are met: 1) evidence of autonomous excess aldosterone production based on an ARR $>30 ; 2$ ) lateralization of aldosterone secretion at AVS or during dexamethasone suppression adrenocortical scintigraphy; 3 ) evidence of a nodule on CT scan; and 4) postsaline loading (PAC $>10 \mathrm{ng} / \mathrm{dl}$ ) and/or a pathologically proved adenoma after adrenalectomy and cure of hypertension without antihypertensive agents or improved hypertension, potassium, PAC, and PRA. On the other hand, IHA (or BAH) can be diagnosed with the following criteria:

1) Evidence of autonomous excess aldosterone production based on ARR > 30,

2) non-lateralization of aldosterone secretion at AVS or dexamethasone suppression adrenocortical scintigraphy; 3) evidence of bilateral diffuse enlargement on CT scan, and/or 4) postsaline loading $(\mathrm{PAC}>10 \mathrm{ng} / \mathrm{dl})$ and/or evidence of diffuse hyperplasia of cells on pathologic findings [39].

Apart from the suppression test with infusion of the saline solution (SIT), tests with captopril and losartan are also considered useful to discriminate between APA and IHA. To this purpose, Rossi et al. suggested that cut-off values for PAC of $6.75 \mathrm{ng} / \mathrm{dL}$ after saline and of $13.9 \mathrm{ng} / \mathrm{dL}$ after captopril may be optimal aldosterone cut-off values for discriminating between APA and IHA [40].

Other authors suggest that a post-losartan ARR $>60$ with a PAC $>10 \mathrm{ng} / \mathrm{dL}$ could be more accurate than the captopril test for the diagnosis of PA and for adequately differentiating APA from IHA [39].

Partially diverting from the criteria and the suggestions mentioned above and trying to comply with the criteria indicated by other authors $[4,28]$, we decided to adopt different cut-off values for the confirmation of PA, in particular PA values $\geq 6 \mathrm{ng} / \mathrm{dL}$ after SIT or of ARR $\geq 40$ after captopril.

To a larger extent, we decided to use the approach of a "composite reference standard", in other words to adopt combined criteria (clinical, laboratory and imaging) in the diagnostic work-up of primary aldosteronism [41]

\section{Conclusion}

Results of our observation of a small population of patients investigated for resistant hypertension confirm the increasing frequency of diagnosis of PA, a secondary and potentially correctable form of hypertension.
Furthermore, early detection and treatment of PA in nephrological settings are very important because of the relationship between aldosterone and kidney function. In fact, recent clinical and experimental evidence induces to consider that the excess of aldosterone not only through the production of blood hypertension, but also by itself alone can lead, in the long term, to a higher rate of cardiovascular events and to structural renal damage disproportionate to blood pressure levels [25]. In particular, it is well known that at renal level the prolonged exposition to vasculotoxic effects of aldosterone excess may cause a relative glomerular hyperfiltration, which not only should be considered as an adaptive response to hypertension, but also as a part of a process that, starting from the production of structural abnormalities (of glomerular podocytes, intrarenal vasculature and interstitium) can lead to progressive kidney injury, with proteinuria and declining glomerular filtration rate [22].

\section{References}

1. Funder JW, Carey RM, Fardella C, Gomez-Sanchez CE, Mantero F, et al (2008) Case detection, diagnosis, and treatment of patients with primary aldosteronism: an Endocrine Society clinical practice guideline. J Clin Endocrinol Metab 93:3266-3281.

2. Conn JW (1955) Presidential address. I. Painting background. II. Primary aldosteronism, a new clinical syndrome. J Lab Clin Med 45: 3-17.

3. Mattsson C, Young WF Jr (2006) Primary aldosteronism: diagnostic and treatment strategies. Nat Clin Pract Nephrol 2: 198-208.

4. Young WF (2007) Primary aldosteronism: renaissance of a syndrome. Clin Endocrinol (Oxf) 66: 607-618.

5. Mulatero P, Morello F, Veglio F (2004) Genetics of primary aldosteronism. J Hypertens 22: 663-670.

6. Stowasser M, Fallo F, So A, Jeske Y, Kelemen L, et al. (2007) Genetic forms of primary aldosteronism. High Blood Press Cardiovasc Prev 14: 75-81.

7. Sutherland DJ, Ruse JL, Laidalaw JC (1966) Hypertension, increased aldosterone secretion and low plasma renin activity relieved by dexamethasone. Can Med Assoc J 95: 1109-1119.

8. Lifton RP, Dluhy RG, Powers M, Rich GM, Cook S, et al. (1992) A chimaeric 11-b-hydroxylase/aldosterone syntase gene causes glucocorticoid- remediable aldosteronism and human hypertension. Nature 355: 262-265.

9. Gordon RD, Stowasser M, Tunny TJ, Klemm SA, Finn WL, et al. (1991) Clinical and pathological diversity of primary aldosteronism including a new familial variety. Clin Exper Pharmacol Physiol 18: 283-286.

10. London N, Swales J, Hollinrake K, Bell P, Heagerty A (1992) Familial Conn's Syndrome. Postgrad Med J 68: 976-977.

11. Young WF Jr, Kaplan NM, Rose BD (2011) Clinical features of primary aldosteronism. UpToDate Online 2011, version 19.2

12. Conn JW (1966-1967) The evolution of primary aldosteronism: 1954-1967. Harvey Lect 62: 257-291.

13. Gordon RD, Stowasswer M, Tunny TJ, Klemm SA, Rutherford JC (1994) High incidence of primary aldosteronism in 199 patients referred with hypertension. Clin Exp Pharmacol Physiol 21: 315-318.

14. Kaplan NM (2004) The current epidemic of primary aldosteronism: causes and consequences. J Hypertens 22: 863-869.

15. Kaplan NM (2007) Is there an unrecognized epidemic of primary aldosteronism? Con. Hypertension 50: 454-458.

16. Rossi GP, Bernini G, Caliumi C, Desideri G, Fabris B, et al. (2006) A prospective study of the prevalence of primary aldosteronism in 1,125 hypertensive patients. J Am Coll Cardiol 48: 2293-2300.

17. Douma S, Petidis K, Doumas M, Papaefthimiou P, Triantafyllou A, et al (2008) Prevalence of primary hyperaldosteronism in resistant hypertension: a retrospective obervational study. Lancet 371: 1921-1926.

18. Rossi GP, Seccia MT, Pessina AC (2008) Primary aldosteronism - Part : prevalence, screening, and selection of cases for adrenal vein sampling. $J$ Nephrol 21: 447-454 
Citation: Del Giudice A, Di Giorgio C, Di Giorgio G, Grifa R, Lauriola V, et al. (2012) Increasing Incidence of Primary Aldosteronism in Patients Investigated for Resistant Hypertension: An Observational Study from a Nephrology Unit. J Nephrol Therapeutic S3:007. doi:10.4172/21610959.S3-007

Page 5 of 5

19. Rossi GP, Bernini G, Desideri G, Fabris B, Ferri C, et al. (2006) Renal damage in primary aldosteronism: results of the PAPY Study. Hypertension 48: 232238.

20. Sechi LA, Novello M, Lapenna R, Baroselli S, Nadalini E, et al. (2006) Longterm renal outcomes in patients with primary aldosteronism. JAMA 295: 26382645.

21. Rossi GP, Sechi LA, Giacchetti G, Ronconi V, Strazzullo P, et al. (2008) Primary aldosteronism: cardiovascular, renal and metabolic implications. Trends Endocrinol Metab 19: 88-90.

22. Wu VC, Kuo CC, Wang SM, Liu KL, huang KH, et al. (2011) Primary aldosteronism: changes in cystatin $\mathrm{C}$-based kidney filtration, proteinuria, and renal duplex indices with treatment. J Hypertens 29: 1778-1786.

23. Hollemberg NK (2004) Aldosterone in the development and progression of renal injury. Kidney Int 66: 1-9.

24. Marney AM, Brown NJ (2007) Aldosterone and end-organ damage. Clin Sci (Lond) 113: 267-278.

25. Milliez P, Girerd X, Plouin PF, Blacher J, Safar ME, et al. (2005) Evidence for an increased rate of cardiovascular events in patients with primary aldosteronism. J Am Coll Cardiol 45:1243-1248.

26. Schrier RW, Masoumi A, Elhassan E (2010) Aldosterone: role in edematous disorders, hypertension, chronic renal failure, and metabolic syndrome. Clin J Am Soc Nephrol 5: 1132-1140

27. Mulatero P, Stowasser M, Loh KC, Fardella CE, Gordon RD, et al. (2004) Increased diagnosis of primary aldosteronism, including surgically correctable forms, in centers from five continents. J Clin Endocrinol Metab 89: 1045-1050.

28. Mulatero P, Bertello C, Rossato D, Mengozzi G, Milan A, et al. (2008) Roles of clinical criteria, computeds can, and adrenal vein sampling in differential diagnosis of primary aldosteronism subtypes. J Clin Endocrinol Metab 93: 1366-1371.

29. Fagugli RM, Taglioni C (2011) Changes in the perceived epidemiology of primary hyperaldosteronism. Int J Hypertens 162804

30. Olivieri O, Ciacciarelli A, Signorelli D, Pizzolo F, Guarini P, et al. (2004) Aldosterone to renin ratio in a primary care setting: the Bussolengo study. $J$ Clin Endocrinol Metab 89: 4221-4226.
31. Jansen PM, Boosma F, van der Meiracker AH (2008) Aldosterone-to-renin ratio as a screening test for primary aldosteronism--the Dutch ARRAT Study. Neth J Med 66: 220-228.

32. Nishikawa T, Omura M, Satoh F, Shibata H, Takahashi K, et al. (2009) Guidelines for the diagnosis and treatment of primary aldosteronism--the Japan Endocrine Society 2009. Endocr J 58: 711-721.

33. Kaplan NM (2011) Primary aldosteronism: a contrarian view. Rev Endocr Metab Disord 12: 49-52.

34. Montori VM, Young WF Jr. (2002) Use of plasma aldosterone concentrationto- plasma renin activity ratio as a screening test for primary aldosteronism: a systematic review of the literature. Endocrinol Metab Clin North Am 31: 619632

35. Mattsson C, Young WF Jr. (2006) Primary aldosteronism: diagnostic and treatment strategies. Nat Clin Pract Nephrol 2: 198-208.

36. Conn JW, Cohen EL, Rovner DR, Nesbit RM (1965) Normokalemic primary aldosteronism: a detectable cause of curable "essential" hypertension. JAMA 193: $200-206$

37. Nishikawa T, Omura M (2000) Clinical characteristics of primary aldosteronism its prevalence and comparative studies on various causes of primary aldosteronism in Yokohama Rosai Hospital. Biomed Pharmacother 54: 83-85.

38. Omura M, Saito J, Yamaguchi K, Kakuta Y, Nishikawa T (2004) Prospective study on the prevalence of secondary hypertension among hypertensive patients visiting a general outpatient clinic in Japan. Hypertens Res 27: 193202.

39. Wu VC, Chang HW, Liu KL, Lin YH, Chueh SC, et al. (2009) Primary aldosteronism: diagnostic accuracy of the losartan and captopril tests. Am J Hypertens 22: 821-827.

40. Rossi GP, Belfiore A, Bernini G, Desideri G, Fabris B, et al. (2007) Comparison of the captopril and the saline infusion tests for excluding aldosterone-producing adenoma. Hypertension 50: 424-431.

41. Rutjes AW, Reitsma JB, Coomarasamy A, Khan KS, Bossuyt PM (2007) Evaluation of diagnostic tests when there is no gold standard. A review of methods. Health Technol Assess 11: 9-51. 